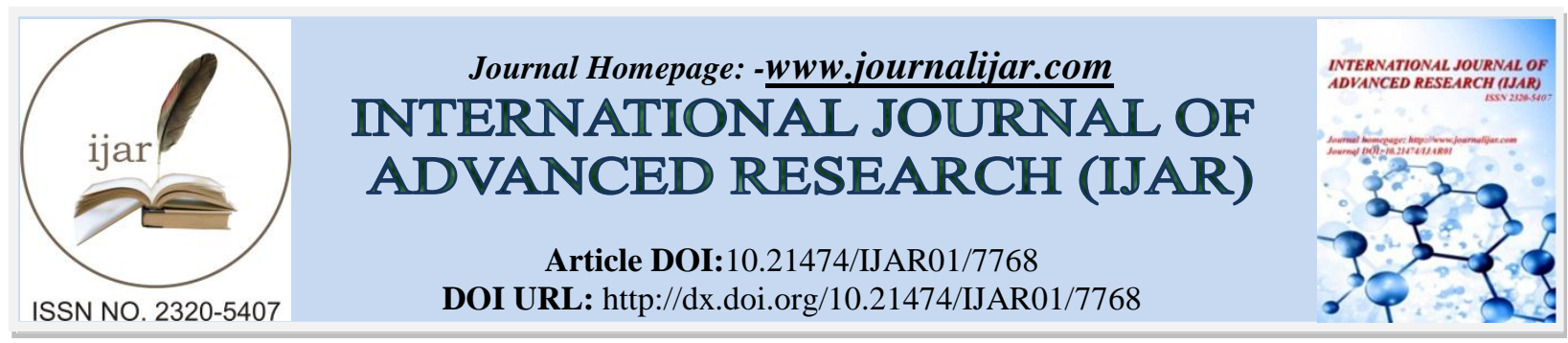

RESEARCH ARTICLE

\title{
A PERSPECTIVE:THE USE OF GUIDED IMAGERY AND DRAWINGS AS AN ALTERNATIVE TREATMENT FOR CHILDREN OF TRAUMA.
}

\author{
Brandi Phillips \\ MASaybrook University 806-559-2503.
}

\section{Manuscript Info}

Manuscript History

Received: 25 July 2018

Final Accepted: 31 August 2018

Published: September 2018

Keywords:-

guided imagery, anxiety, re-experiencing

trauma, internal dialogue.

\begin{abstract}
Cognitive behavioral therapy and pharmaceuticals have traditionally been used to treat trauma-related anxiety in children. Imagery Rehearsal Therapy and meditative breathing with guided imagery have been used as alternative treatments to help reduce the nightmares, regain the sense of control, and rescript the negative internal dialogue created by the trauma-related anxiety. Combining drawing techniques with these mind-body therapies to treat trauma-related anxiety in children is explored as a possible method to better understand the way children perceive treatment and assess their own progress.
\end{abstract}

Copy Right, IJAR, 2018,. All rights reserved.

\section{Introduction:-}

Trauma-Related Anxiety in Children:

The Use of Guided Imagery and Drawings as an Alternative Treatment for Children of TraumaAn estimated four million children are exposed to trauma each year (Swiech, 2012). In the United States alone, 7.8\% of the population seeks treatment for stress disorders, and the diagnosis rate is highest among childhood trauma victims (Swiech, 2012).

A major long-term impact from trauma-related anxiety is based on the intense fear or sense of threat at the time of the trauma. It continues past the trauma through the maladaptation of the child to times when there is no threat (Meiser-Stedman et al., 2007). Trauma-related anxiety leads to intrusive thoughts or images of trauma in the form of nightmares, dissociative behavior, and a perceived loss of control in their lives (Liotti, 2004).The purpose of this paper is to examine imagery as an alternative psychotherapeutic method to help lessen the anxiety symptoms experienced for children of trauma.

\section{Symptoms of Trauma in Children of Abuse}

Children have been found to use two types of coping when dealing with anxiety of trauma (Hager \& Runtz, 2012, \& Khamis, 2015). Each of these coping techniques will be discussed and how they are expressed differently throughout developmental stages.

\section{Types of coping}

The first type of coping is emotion-focused coping which includes disengaging from emotions associated with the triggers or stressors and venting emotions felt from re-experiencing the trauma (Hager \& Runtz, 2012). The second is problem-focused coping which causes anxiety because the child is focused on the problem and how they can solve it 
(Khamis, 2015). This can be destructive because children usually cannot control the trauma.

Trying to control the traumatic experience and replaying the internal scripts that run through their minds are part of the grieving process. According to the Kubler-Ross model (1969), there are five stages of grief: denial, anger, bargaining, depression, and acceptance. Many children of traumaare stuck in the bargaining stage of grief. In an attempt to rationalize what they have been told and been through, they try to reconcile it with their current actions.

\section{Ways of expressing anxiety}

Whether children are using either type of coping technique, children of trauma also express that anxiety in different ways according to their developmental stage. Preschoolers express negative affect (a blank stare or constant frown), avoidance, and noncompliance (Crawford, Schrock, \& Woodruff-Borden, 2011). Children, ages 6 to 12, display low self-worth, rejection from peers, aggression towards peers, suffer from depression, and present conduct issues. Adolescents, particularly those that have experienced trauma, express dissociative symptoms and substance abuse as a form of avoidance (Marshall, 2012).

Although historically children suffering from anxiety from trauma have been treated with medications such as antidepressants and antipsychotics to help with insomnia and recurrent nightmares (Robert et al., 1999), 8.8\% of adolescents (ages 12-17) have started using these pharmaceuticals for non-medicinal uses (National Institute of Drug Abuse, 2015). Therefore, it is becoming more acceptable to use mind-body techniques (non-pharmaceutical methods) like guided meditation with children to reduce stress (Staples, Abdel, \& Gordon, 2011). A technique, like guided imagery, that can help recreate the internal dialogue and restore a sense of control over anxiety symptoms, may be the alternative treatment necessary to treat children of trauma.

\section{The Use of Imagery for Reprogramming Inner Dialogue}

Recreating the inner dialogue of children of trauma may be accomplished through guided imagery. Variations of imagery rescripting, like imagery rehearsal therapy (IRT), have supported a change in individuals of trauma that reprograms the sensory output associated with traumatic experiences (Long et al., 2011). According to Long et al. (2011), trauma-related images are problematic because "the traumatized individual frequently believes the distorted images to be a reflection of reality, resulting in chronic collaboration of negative beliefs, avoidance, and hyperarousal symptoms" (p. 1009). How the reprogramming through IRT can reflect new, positive beliefs after the individual gains control over the images and how this therapy can be modified for success with children will be discussed.

\section{Imagery Rehearsal Therapy}

Gaining control over the images through IRT is done is a three-step cognitive-behavioral process while in a state of relaxation (St-Onge, Mercier, \& De Koninck, 2009). First, the client is asked to modify the image content to reflect the new belief. Next, the client is asked to visualize the new image. This is the cognitive interventional part of the treatment. Then, the client is asked to rehearse this visualization while in meditation. This is the behavioral part of the treatment (St-Onge, Mercier,\& De Koninck, J., 2009, p.82).

In a study by St-Onge, Mercier, and De Koninck, (2009), the three-part treatment was applied to 20 children of trauma, ages 9-11, experiencing reoccurring nightmares. The major trauma present was related to familial situations, and hyperarousal symptoms were present in all children (p. 84-85). After baseline measurements were taken, the children were asked to complete a four week journal about their nightmares. The treatment meetings started taking place after the initial four weeks of journaling. In the treatment meetings, the 10 experiential participants experienced the IRT process. They were then told to go home and go through the process for the next four weeks, journaling after waking each day for two months. Parents were given child-appropriate instructions on how to carry-out the exercise and were told to remind the children about journaling. Once a month, a follow-up interview was done to assess distress felt by the participants. Any changes in sleep, life, and medications were reported. The life-related distress was reported on a five-point Likert scale of nine items (St-Onge, Mercier, \& De Koninck, 2009, p. 88).

At the end of the nine months, the researchers' hypothesis that IRT could be effective in reducing nightmares in children was supported. St-Onge, Mercer, and De Konick (2009) explained that the Likert scale results showed the lowered distress related to nightmares from the point of the induction of IRT. The results did not show a retroactive lowering of distress related to nightmares in general. Additionally, the interviews showed evidence that induction of 
the IRT exercises in a single session with the therapist and 10 minute applications at night were sufficient to lower the perceived threat and anxiety related to the trauma re-experienced in the nightmares. St-Onge, Mercer, and De Konick (2009) suggested five factors can account for the effectiveness of IRT with children. First, children have a natural tendency toward imagery. Second, IRT was applied again before going to sleep. This is a time when children are highly susceptible. Third, the children were given a sense of control because they were given the freedom to choose their visualizations rather than being told what to change. Fourth, the IRT intervention happened relatively early in the children participants, as opposed to the previous studies done with adults after long-term trauma induced nightmares. Finally, most children have not formed maladaptive behaviors yet that can inhibit treatment (p. 93-94).

\section{Imagery Rehearsal Therapy with Drawings}

After the successful findings of the St-Onge, Mercer, and De Konick (2009) study, Simard and Nielsen (2009) conducted a similar study with children and IRT. Simard and Nielsen (2009) modified the imagery rehearsal to children's high familiarity of drawing their visualizations. The drawings were meant to give the children a greater sense of control, mastery, and competence. Instead of imagery rehearsal, children were asked to draw modified versions of their last dreams (Simard \& Nielson, 2009, p. 493).

For the modified study, 10 sets of mothers and children attended three sessions of IRT using the drawing adaptations and agreed to take part in an eight week telephone log assessing the frequency and child's perception of the dreams and anxiety associated with the dreams. These daily phone log interviews were done by the child through prerecorded verbal ques. Children were also instructed to draw, daily, a modified version of the last distressing dream they had (Simard \& Nielson, 2009).

The children's anxiety levels were assessed using the Anxiety Disorder Interview Schedule Child Version (ADIS-C) and the Revised Children manifest Anxiety Scale (RCMAS). These were given before the study and at the followup visits. There was a measured decrease in reported anxiety and anxiety symptoms from the second session with both the experimental and control groups, but only continued to decrease in the therapeutic group. Both children and mothers reported no unpleasant dreams from the third session until three months post-treatment (Simard \& Nielson, 2009). These findings suggested mere participation in the study, contact with the psychologist and an understanding of the study, helped to initially reduce anxiety related to trauma. The daily integration of the IRT and its modification with the drawings helped to decrease new unpleasant dreams and the distress related to the new dreams.This conclusion helps to support the idea that guided imagery may help recreate the internal dialogue. Furthermore, the modification of treatments with drawings may restore a sense of control over trauma-related symptoms necessary to treat children of trauma.

\section{Drawings with Imageryto Understand Trauma in Children}

Ångström-Brännström and Norberg (2014) suggested children interpret their therapeutic experiences more positively when they are allowed to assess the treatment both through dialogue and drawings. When evaluating children experiencing trauma because of cancer-related treatments, Ångström-Brännström and Norberg (2014) noted the children expressed their appreciation for feeling understood. They could exercise some control over their fears with mutual respect and understanding. The drawings allowed them to provide insight their vocabulary was limited in doing. As the above described modified IRT supported, drawings may be the key link to helping therapist use guided imagery with children of trauma to rescript their inner dialogue. The drawings may be used to assess their progress and support the children's own understanding of the progress of the treatment.

\section{The Rosebush Technique}

The Rosebush Technique is a guided imagery and drawing combination that has been used to assess the progress of children experiencing trauma. Glazer (1998) conducted a study using the guided fantasy technique in which children relax and imagine themselves as a rosebush. Then, prompted with guided imagery questions, the children drew a picture, and participated in a post-drawing inquiry.

Glazer (1998) conducted a study on three boys and six girls with a median age of 10 who were suffering the loss of a loved one. The children were part of a trauma relief group that met twice a month. The meetings began with a social gathering then moved on to the support groups. It was in the initial and final support group meetings that Glazer and two play therapists conducted the Rosebush Technique to evaluate the children's progress in traumatic experiencing reduction. The Rosebush Technique consists of three phases: relaxation and imagery, drawing, and a 
post-drawing questioning (Glazer, 1998, p. 54). The facilitator started with a relaxation exercise, then the children were asked to image themselves as a rosebush. After the facilitator described the parts of the rosebush, the children were asked to draw what they imagined. The children could use crayons, markers, paints, or pencils.

To evaluate the drawing in the Glazer (1998) study, the researchers developed a coding system. This system assigned values to "the use of words, degree of integration, use of space, and degree of isolation and connectedness" (p. 56). The second round of drawings, after the program treatment, demonstrated less division and isolation of the rosebushes, more lightness, more groundedness, and drawings of suns. The children were questioned about the drawings, and two themes were found: "a movement of isolation to integration and an increased feeling of safety in the world" (Glazer, 1998, p. 56).

The researcher concluded that the Rosebush drawing itself and the feelings which surfaced by creating the drawing were the most important assessment tool to evaluate change in traumatic experiencing. Since children have few coping skills to tolerate emotional pain and limited vocabulary to express their hurt and anger, may children deny the existence of the trauma (Glazer, 1998). Through drawing, the children can express their thoughts and feelings through images rather than words. The symbolic reference to events and objects can then translate into the adult understanding of the tangible world. This metaphoric representation is essential to a therapeutic process with children; "...the child translates images and feelings into movements of shapes and colors in a shared experience with the counselor" (Glazer, 1996, p. 52). Therefore, it is also essential to integrate drawing into assessing any modality of treatment for children of trauma that does not involve a concrete element.

\section{Self-Expression after Mind-Body Interventions}

This integration of drawing for assessment of treatments using guided imagery was also part of a study used by Staples, Abdel, and Gordon (2011) to gauge the progress of children of trauma in the Gaza strip. The drawings were used to assess optimism about the future and reduction of intrusion and arousal symptoms related to trauma. The drawings were done after an initial guided imagery session and after treatment.

Staples, Abdel, and Gordon (2011) examined 571 child and adolescent trauma victims in Gaza and their use of breathing techniques and guided imagery to self-regulate emotion. The children attended mind-body skills groups for two hours, twice a week, and 10 sessions in total. There were 8-10 children per group. During the second session, the children used controlled, meditative breathing techniques and were asked to draw three drawings: how you feel now, your main problem, and how you would be if the problem was solved (Staples, Abdel, and Gordon, 2011, p. 251). The following session, the childrenwere taught how to use autogenic, or self-generated, phrases. Autogenic phrases are a repetitive set of words used over and over to reflect the emotional state of a person in meditation. This repetition allows the person to become entranced in a transcendental meditative state (Anderson, 2014). This allowed children to slow their breathing, become calm, then work through their trauma experiences, giving them a sense of control over the symptoms. This sense of control reduced intrusive thoughts and arousal symptoms (Staples, Abdel, and Gordon, 2011). In the fourth session, the children used a "safe place" guided imagery to induce relaxation when stress surfaces and a "wise guide" guided meditation to gain access to their intuition. More mind-body techniques were taught in subsequent sessions. During the tenth, and final session, the children were once again asked to draw the three drawings. They shared the differences and similarities between pre-treatment and post-treatment drawings.

Staples, Abdel, and Gordon (2011) found that, while sharing the differences in the drawings, the children expressed feeling calmer and less loneliness and isolation. The researchers discovered the safe place guided imagery and wise guide imagery combined with the drawingsallowed the children to uncover "intuitive solutions to anxiety and chronic problems related to trauma". The drawings helped the children express what they could not in words and assess their progress from the treatment, only reinforcing the autonomy to get through the anxiety related to trauma (Staples, Abdel, \& Gordon, 2011, p. 259).

\section{Conclusion:-}

Maladaptation of the trauma-related anxiety can lead to long-term intrusive thoughts or images of trauma in the form of nightmares, dissociative behavior, and a perceived loss of control in children's lives. The ability to regain the sense of control in their lives is a key component to treating this anxiety. When children already feel an inability to effectively communicate their frustrations or anger to adults, it only compounds the anxiety felt when children are being treated for nightmares and other coping issues related to trauma. 
The use of guided imagery to rescript trauma-related nightmares or intrusive thoughts through IRT or meditative breathing with guided imagery has been shown to help those suffering from the debilitating anxiety associated with trauma. Once the addition of drawings were used to modify the treatments and allow children to use images where they did not have the words to express their trauma, the mind-body treatments showed success with the populations. The success led to less trauma-related anxiety, lower incidences of nightmares, a lower feelings of isolation, a greater sense of connectedness, and sense of regaining some control in their lives. Because drawings help to improve the communication between child and therapist, the use of drawings with guided imagery may be a key to successful treatment of trauma-related anxiety in children.

\section{References:-}

1. Anderson, C. M. (2014). Biopsychosocial treatment of hypertension: An individual outcomestudy (Unpublished doctoral dissertation). University of Johannesburg, Johannesburg, South Africa.

2. Ångström-Brännström, C., \& Norberg, A. (2014). Children undergoing cancer treatment describe their experiences of comfort in interviews and drawings. Journal of Pediatric Oncology Nursing, doi:1043454214521693.

3. Crawford, N. A., Schrock, M., \& Woodruff-Borden, J. (2011). Child internalizing symptoms: Contributions of child temperament, maternal negative affect, and family functioning.Child Psychiatry \& Human Development, 42(1), 53-64.

4. Glazer, H. R. (1998). Expressions of Children's Grief: A qualitative study. International Journalof Play Therapy, 2(7), 51-65.

5. Hager, A. D., \& Runtz, M. G. (2012). Physical and psychological maltreatment in childhood and laterhealth problems in women: An exploratory investigation of the roles of perceived stress and coping strategies. Child Abuse \& Neglect, 36(5), 393-403.

6. Khamis, V. (2015). Coping with war trauma and psychological distress among school-agePalestinian children. American Journal of Orthopsychiatry, 85(1), 72-79. doi:10.1037/ort0000039

7. Liotti, G. (2004). Trauma, dissociation, and disorganized attachment: Three strands of a single braid. Psychotherapy: Theory, Research, Practice, Training, 41(4), 472-486. doi:10.1037/0033-3204.41.4.472

8. Long, M., Davis, J., Springer, J...Frueh, B.C. (2011). The role of cognitions in imageryrescripting for posttraumatic nightmares. Journal of Clinical Psychology, 67(10), 1008-1016.

9. Marshall, N. A. (2012). A clinician's guide to recognizing and reporting parental psychological maltreatment of children. Professional Psychology: Research and Practice, 43(2), 73-79. doi:10.1037/a0026677

10. Meiser-Stedman, R., Dalgleish, T., Smith, P., Yule, W., \& Glucksman, E. (2007). Diagnostic, demographic, memory quality, and cognitive variables associated with acute stress disorder in children and adolescents. Journal of Abnormal Psychology, 116(1), 65-79.

11. National Institute of Drug Abuse (2015). Retrieved from http://www.drugabuse.gov/national-

12. survey-drug-use-health Robert, R., Blakeney, P. E., Villarreal, C., Rosenberg, L., \& Meyer, W. J. (1999). Imipramine treatment in pediatric burn patients with symptoms of acute stress disorder: a pilot study. Journal of the American Academy of Child \& Adolescent Psychiatry, 38(7), 873-882.

13. Simard, V. \& Nielsen, T. (2009). Adaptation of imagery rehearsal therapy for nightmares in children: A brief report. Psychotherapy Theory, Research, Practice, Training, 46(4), 492-497.

14. St-Onge, M., Mercier, P., \& e Koninck, J. (2009). Imagery Rehearsal Therapy for Frequent Nightmares in Children. Behavioral Sleep Medicine, 7, 81-98.

15. Staples, J. K., Abdel Atti, J. A., \& Gordon, J. S. (2011). Mind-body skills groups for posttraumatic stress disorder and depression symptoms in Palestinian children and adolescents in Gaza. International Journal of Stress Management, 18(3), 246-262. doi:10.1037/a0024015

16. Swiech, P. (2012, December 7). Children can also suffer from PTSD. The Pantagraph(Bloomington, IL). 